\title{
Evaluación aeromicrobiológica del depósito del Centro de Documentación del Museo Nacional de la Música de Cuba
}

\author{
Julio César Rodríguez García
}

Resumen: El estudio tuvo como objetivos la caracterización de la microbiota aérea del local para evaluar el riesgo potencial de microbiodeterioro de colecciones documentales de valor patrimonial. Se realizó a través del método de sedimentación y pruebas fisiológicas cualitativas que permitieron conocer la actividad biodeteriógena de la micobiota aislada, teniendo en cuenta el papel de los hongos en el biodeterioro de colecciones de naturaleza orgánica. Se demostró una fuerte correlación positiva entre temperatura (T) y humedad relativa (HR) respecto a la concentración fúngica del aire y la concentración microbiana fue significativamente superior en época de lluvia, con una mayor concentración de bacterias en ambos muestreos. Según los criterios de Omeliansky el ambiente estaba altamente contaminado en época lluviosa para hongos y bacterias, mientras en época de seca no presentaba contaminación fúngica. En ambos muestreos predominaron representantes de los géneros Aspergillus, Penicillium y Cladosporium, y bacterias Gram positivas. Los aislados fúngicos con mayor densidad relativa mostraron un elevado poder de deterioro, que destaca la necesidad del control de los parámetros climáticos como mejor método de control del biodeterioro de bienes patrimoniales.

Palabras clave: aerobiología, biodeterioro, hongos, bacterias, sedimentación, conservación

\section{Aeromicrobiological Evaluation in repository of the Documentation Center of the National Museum of Music of Cuba}

\begin{abstract}
The study aimed to characterize the microbiota air local to evaluate the potential risk of biomicrodeterioration in documentary collections. It was performed through the sedimentation method and qualitative physiological tests to know the biodeterioration power of isolated fungi in organic collections. A strong positive correlation between temperature (T) and relative humidity (RH) to the concentration fungal and microbial air concentration showed was significantly higher in rainy season, with a higher concentration of bacteria in both samples. According to the criteria of Omeliansky the atmosphere was highly polluted during the rainy season for fungi and bacteria, while during the dry season showed no fungal contamination. In both samples were predominant representatives of the genera Aspergillus, Penicillium and Cladosporium, and Gram positive bacteria. More fungal isolates showed a high density relative to deterioration, which highlights the need for control of climate parameters such as better control method biodeterioration of cultural heritage objects.
\end{abstract}

Key words: aerobiology, biodeterioration, fungi, bacteria, sedimentation, conservation

\section{Avaliação aéreo microbiológica do depósito do Centro de Documentação do Museu da Música de Cuba}

Resumo: Este estudo teve como objetivos a caracterização da microbiota aérea do local para avaliar o risco potencial de deterioração biomicro das colecções documentais de valor patrimonial. Este estudo realizou-se através do método de sedimentação e de testes fisiológicos qualitativos que permitiram conhecer a atividade biodeteriógena da microbiota isolada, tendo em conta o papel dos cogumelos na biodetiorização das colecções de natureza orgânica. Demonstrou-se existir uma forte correlação positiva entre a temperatura $(T)$ e a humidade relativa $(\mathrm{HR})$ em relação à concentração do ar e à concentração microbiana que foi significativamente superior na época das chuvas, com uma concentração maior de bactérias em ambas as amostras. De acordo com os critérios de Omeliansky, o ambiente estava altamente contaminado durante a época das chuvas para os cogumelos e para as bactérias enquanto que na época seca não existe contaminação fúngica. Em ambas as amostras predominam representantes do tipo Aspergillus, Penicillium e Cladosporium e bactérias Gram. Os isolados fúngicos com maior densidade relativa mostraram um elevado poder de detiorização, que destaca a necessidade de controle dos parâmetros climatológicos como sendo o melhor método de controle da biodetiorização de bens patrimoniais. 


\section{Introducción}

Los estudios aerobiológicos ganan cada día más importancia en el ámbito de la conservación del Patrimonio Cultural al permitir conocer la carga microbiana en ambientes interiores y valorar el potencial biodeteriógeno que los microorganismos pueden desempeñar en los procesos de deterioro, lo cual está íntimamente relacionado al control de los parámetros climáticos.

En condiciones ambientales apropiadas, la microbiota del aire puede coexistir con las colecciones de valor patrimonial y con las personas en un ecosistema específico sin causar grandes daños. Sin embargo, al producirse un incremento de temperatura $(T)$ y humedad relativa (HR), los microorganismos pueden tener efectos negativos sobre las colecciones, acelerándose su deterioro a partir de su crecimiento y desarrollo vegetativo sobre la superficie de los ejemplares de estas colecciones (Nugari \& Roccardi, 2001; Pinzari et al., 2004; Toivola et al., 2002), así como en la salud de las personas responsables de su conservación (Crespo \& Viñas, 1984; Valentin, 1984), de ahí que para los especialistas de la conservación de bienes patrimoniales tenga gran interés el conocimiento de la concentración microbiana del aire interior de los locales destinados a su almacenamiento y exhibición.

El biodeterioro de materiales bibliográficos se produce, sobre todo, a causa de microorganismos heterótrofos capaces de degradar,através delaexcreción deenzimasyotrosmetabolitos intermediarios, como los ácidos orgánicos, los materiales presentes en las colecciones documentales (Caneva et al. 2000; Arroyo, 1995). Entre los microorganismos destacan los hongos y bacterias aerotransportadas (Bogomolova \& Kirtsideli, 2009). Los hongos son microorganismos cosmopolitas que pueden crecer sobre numerosos tipos de sustratos por lo que juegan un papel esencial en el biodeterioro de materiales de naturaleza orgánica y son fácilmente dispersados por el aire.

Teniendo en cuenta el valor patrimonial de las colecciones documentales que alberga el Centro de Documentación y Archivo del Museo Nacional de Música de Cuba, y el potencial biodeteriógeno de los microorganismos sobre colecciones de naturaleza orgánica, los objetivos de este trabajo fueron evaluar la concentración microbiana y caracterizar la micobiota aislada del aire interior del local que alberga estas colecciones para evaluar el riesgo potencial de biodeterioro de una valiosa colección del Patrimonio Musical cubano, estudio pionero de este tipo en esta institución.

\section{Materiales y métodos}

\section{Local y puntos de muestreo}

El estudio se realizó en el depósito del Centro de Documentación y Archivo perteneciente al Museo Nacional de la Música, ubicado en el centro histórico de La Habana, Cuba. Se realizaron dos muestreos, uno en Junio
2008 (época de lluvia) y otro en Febrero 2009 (época de seca). Las dimensiones del local son: $19.30 \mathrm{~m}$ de largo, 9.30 $\mathrm{m}$ de ancho y $4.70 \mathrm{~m}$ de altura. Se muestrearon un total de 8 puntos según las dimensiones del local teniendo en cuentalos criterios de Sanchis (2002), así como la cercanía a entradas de aire y zonas de trabajo frecuente.

\section{Medición de temperatura y humedad relativa}

Durante los muestreos los valores de T y HR del local se midieron puntualmente empleando un psicrómetro de molinete.

\section{Muestreo microbiológico del aire}

Los muestreos se realizaron por triplicado en cada punto, según el método de sedimentación descrito por Omeliansky (Bogomolova \& Kirtsideli, 2009). Se expusieron placas Petri de $110 \mathrm{~mm}$ de diámetro a una altura de 1.5 $\mathrm{m}$ durante 5 min que contenían Agar Extracto de Malta suplementado con $\mathrm{NaCl}$ (7.5\%) para el aislamiento fúngico y Agar Triptona Soya para para el aislamiento bacteriano. Las placas se incuban a $28^{\circ} \mathrm{C}$ durante 7 a 10 días para el aislamiento de hongos, y a $37^{\circ} \mathrm{C}$ por 24 a 48 horas para el aislamiento de bacterias. Concluida la incubación, se realizó el conteo de unidades formadoras de colonia para determinar la concentración microbiana del aire, expresada en unidades formadoras de colonias por $\mathrm{m}^{3}$ de aire $\left(u f c \cdot \mathrm{m}^{-3}\right.$ ) según la ecuación descrita por Omeliansky:

$$
\begin{aligned}
& \mathrm{N}=5 \mathrm{a} \cdot 10^{4}(\mathrm{~b} . \mathrm{t})^{-1} \\
& \mathrm{~N} \text { - concentración microbiana en ufc. } \mathrm{m}^{-3} \\
& \mathrm{a}=\text { número de colonias por placa Petri, } \\
& \mathrm{b}=\text { es la superficie de la placa }\left(\mathrm{r}^{2} \times \pi\right) \text { expresada en } \mathrm{cm}^{2} \\
& \mathrm{t}=\text { tiempo de exposición en minutos. }
\end{aligned}
$$

Para determinar el grado de contaminación se compararon las concentraciones microbianas obtenidas con la escala propuesta por Omeliansky.

\section{Identificación y caracterización microbiana}

Se depuraron las diferentes colonias emergentes. Para la identificación de los hongos se emplearon técnicas tradicionales siguiendo los criterios de Barnett \& HUNTER (1987), Casadesús \& Rojas (1981), Pitt \& Klich (1994) y Pitt (2000) y se determinaron las densidades relativas (DR) de las cepas aisladas según Smith (1980). Para la identificación de grupos bacterianos se realizó la observación de las colonias al microscopio estereoscopio para apreciar sus características culturales y la tinción de Gram. La caracterización cualitativa del poder deteriorante de los aislados fúngicos con mayor densidad relativa se llevó a cabo mediante el estudio de la excreción de ácido; determinación cualitativa de la actividad celulolítica y proteolítica y la producción de ácidos (Borrego, 2010). 


\section{Análisis estadístico}

El análisis estadístico de los datos se realizó con el programa Start Graphic Centurion XV. Se analizó la distribución de probabilidad mediante prueba de t-student para un 95 $\%$ de confianza $(p<0,05)$. Los datos obtenidos de factores físicos y concentración microbiana se analizaron mediante la correlación de Spearman. Para determinar la significación del efecto de las condiciones del muestreo se aplicó un análisis de varianza (ANOVA) de clasificación simple para cada muestreo complementado con la prueba de Duncan.

\section{Resultados y discusión}

\section{Concentración microbiana del aire interior del depósito}

Es conocido el empleo de metodologías de impactación para la realización de este tipo de estudios, pero teniendo en cuenta la carencia de muestreadores activos, como el biocolector SAS, en el ámbito de nuestras instituciones museales y que el método de sedimentación ha sido estandarizado desde el 2004 para la cuantificación de la microbiota en ambientes interiores de museos, archivos y bibliotecas por Borrego y col. (Borrego, 2004; Borrego et al., 2008; Borrego et al., 2010a; Borrego et al., 2010b; Borrego \& García, 2011; Borrego et al., 2011; Borrego \& Perdomo, 2012), el estudio se realizó mediante esta última metodología, ampliamente reportada en estudios aerobiológicos en el mundo entero (Abdel Hameed et al. 2012; Awad Y Mawla, 2012).

En los últimos años muchos grupos de investigadores internacionales validan el empleo del método de viables por sedimentación para la realización de este tipo de estudios. En sus resultados se reportan concentraciones fúngicas generalmente en el rango de ambientes de poco a no contamiandos, aunque en dependencia de la variación de los parámetros que influyen en la liberación y sedimentación de las esporas y otros propágulos fúngicos, estos pueden ser superiores alcanzando el orden de ambientes contaminados (Kasprzyk \& Worek, 2006; Ulea et al., 2008; Yassin \& Almouqatea, 2010; StryjakowskaSekulska et al., 2007; Novakovic et al., 2013). Por otro lado,
Pasquarella et al. (2000) reportan que cada muestreador activo ofrece resultados diferentes en el mismo lugar y al mismo tiempo demostrando una alta variabilidad, además de reportar una serie de desventajas importantes para este tipo de equipos que pueden incidir significativamente en los resultados del muestreo.

Teniendo en cuenta estos planteamientos y valorando los objetivos de nuestro estudio, destinado a la caracterización de la microbiota deambientesinteriores de museos, archivos y bibliotecas, directamente relacionada con los posibles procesos de deterioro de los materiales constituyentes de los bienes atesorados en estas instituciones, se considera que el método empleado es efectivo al permitir cuantificar y caracterizar una micobiota ampliamente diversa que entra en contacto con la superficie de las colecciones precisamente por la sedimentación gravitacional de sus propágulos.

A partir de los resultados obtenidos [Tabla 1] se detectaron concentraciones fúngicas y bacterianas de 825 ufc. $\mathrm{m}^{-3}$ y 1531 ufc. $\mathrm{m}^{-3}$ respectivamente en el muestreo realizado en Junio 2008 y de 128 ufc.m ${ }^{-3}$ y 900 ufc.m $^{-3}$ en el muestreo de Febrero 2009, existiendo diferencias significativas entre ambos grupos microbianos y entre ambos muestreos. Según los rangos propuestos por Omliansky y otros reportes más recientes el ambiente se encuentra altamente contaminado respecto a la carga bacteriana y microbiana total siendo ligeramente contaminado con respecto a la carga fúngica, resultados que se corresponden con las concentraciones microbianas normalmente encontradas en los ambientes interiores similares (Cassares, 2007).

El análisis estadístico arrojó además la existencia de diferencias significativas entre las concentraciones fúngicas y de microorganismos totales encontrados en ambos muestreos, siendo significativamente superior en Junio 2008 donde se registraron valores superiores de $\mathrm{T}$ y $\mathrm{HR}$, variables cuyo aumento favorece el incremento de las concentraciones microbianas detectadas en el aire interior así como la posibilidad de infestaciones activas, especialmente fúngicas, que ponen en riesgo de biodeterioro los materiales de las colecciones documentales.

Tabla 1.- Concentración microbiana del aire del depósito del Centro Documental y Archivo del Museo Nacional de la Música en los muestreos realizados en Junio 2008 (lluvia) y Febrero 2009 (seca)

\begin{tabular}{|c|c|c|c|c|c|}
\hline Muestreo & Hongos ufc.m ${ }^{-3}$ & Bacterias ufc.m ${ }^{-3}$ & $\begin{array}{c}\text { Microorganismos } \\
\text { Totales }^{1}\end{array}$ & HR (\%) ${ }^{a}$ & $\mathrm{~T}(\mathrm{OC})^{\mathrm{a}}$ \\
\hline $\begin{array}{l}\text { Junio } 2008 \\
\text { (lluvia) }\end{array}$ & $825,4^{*}$ & 1531,3 & $2356,7^{*}$ & 76 & 28 \\
\hline $\begin{array}{l}\text { Febrero } 2009 \\
\text { (seca) }\end{array}$ & $128,9^{*}$ & 900,6 & $1029,5^{*}$ & 61 & 21 \\
\hline
\end{tabular}

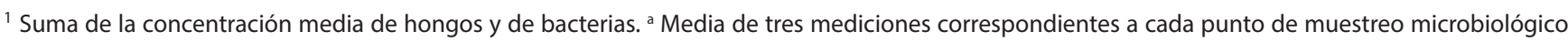
$(\mathrm{n}=8)$. * Diferencias significativas según prueba de t-student para $95 \%$ de confianza $(\mathrm{p}<0,05)$ 
Aunque no existe una norma internacional que establezca los límites para clasificar a un ambiente interior de contaminado o no, la OMS plantea que por encima de 1000 ufc. $\mathrm{m}^{-3}$ los ambientes se consideran contaminados (Nevalainen \& Morawska, 2009). En Brasil se considera que un ambiente interior con más de 700 ufc. $\mathrm{m}^{-3}$ de hongos, está contaminado (Radler de Aquino \& De Góes, 2000), en tanto que en otros casos se plantea que concentraciones fúngicas igual o mayor a 300 ufc. $\mathrm{m}^{-3}$ corresponden a ambientes contaminados (Kolwzan et al. 2006), mientras autores italianos refieren que 150 ufc. $\mathrm{m}^{-3}$ debe ser el límite de hongos permisibles para que el ambiente interior de locales de instituciones patrimoniales se considere de calidad (Cappitelli et al. 2009).

Niveles de concentración microbiana similares han sido reportados en Cuba en ambientes interiores de viviendas, bibliotecas, archivos y museos, muestreados con biocolectores y con el método de sedimentación (Rojas \& Martínez, 2000; Pons \& Rojas, 2003; Borrego, 2005). Sin embargo, estudios previos realizados en depósitos del Archivo Nacional de la República de Cuba utilizando el método de sedimentación reportan concentraciones significativamente menores (BORREGO et al. 2007). Esto demuestra la necesidad de realizar muestreos sistemáticos para conocer la variabilidad de la microbiota del aire en ambientes interiores y que la elevada concentración microbiana detectada en este estudio puede deberse a una alta concentración microbiana en el exterior de la edificación debido a la generación de gran cantidad de material particulado, que penetra al depósito a través del sistema de ventilación natural implementado.

Respecto a la época del año en que se realiza el muestreo, las diferencias estadísticamente significativas encontradas, especialmente respecto a las cargas fúngica y microbiana total, reafirma el efecto de la HR en las concentraciones microbianas de un ambiente interior. Este resultado puede deberse a la variación de la HR promedio entre ambos muestreos (de 61 a $76 \%$ ) y la existencia de una muy alta correlación positiva $(0,8677)$ entre la concentración fúngica y la HR, en correspondencia con otros estudios realizados en Cuba y el mundo, especialmente aquellos que utilizan como método de muestreo el método de sedimentación por gravedad (Stryjakowska-Sekulska et al. 2007; Ulea et al. 2009; Abdel Hameed et al. 2012; Awad y Mawla, 2012; Novakovic et al. 2013).

Los altos valores de HR facilitan la sedimentación de las esporas fúngicas aerotransportadas al provocar un crecimiento higroscópico de las mismas, lo que significa incremento del diámetro aerodinámico de la partícula por condensación o absorción de agua que influye en la deposición y cinética del aerosol, aunque no debe obviarse el hecho de que los géneros fúngicos presentes puede ser también un factor que influya de manera significativa en esta correlación teniendo en cuenta las características morfológicas, modos de liberación y transportación de sus esporas. La concentración fúngica mostró además una correlación positiva muy alta $(0,8566)$ con la temperatura, evidenciándose que existe una combinación óptima T-HR para el crecimiento de este grupo microbiano. Por su parte, las concentraciones bacterianas obtenidas en este estudio no mostraron correlación con las variables climáticas analizadas.

\section{Caracterización de la micobiota aérea aislada}

Como se aprecia en la figura 1, durante el muestreo de Junio 2008 la densidad relativa de los géneros fúngicos aislados muestra que el género Aspergillus resultó el de mayor densidad con $37.4 \%$, seguido por los géneros Penicillium y Cladosporium con $19.2 \%$ y $13.8 \%$ respectivamente, lo que se corresponde con resultados de otros muestreos realizados por nuestro laboratorio y otros grupos de trabajo, que señalan a estos géneros

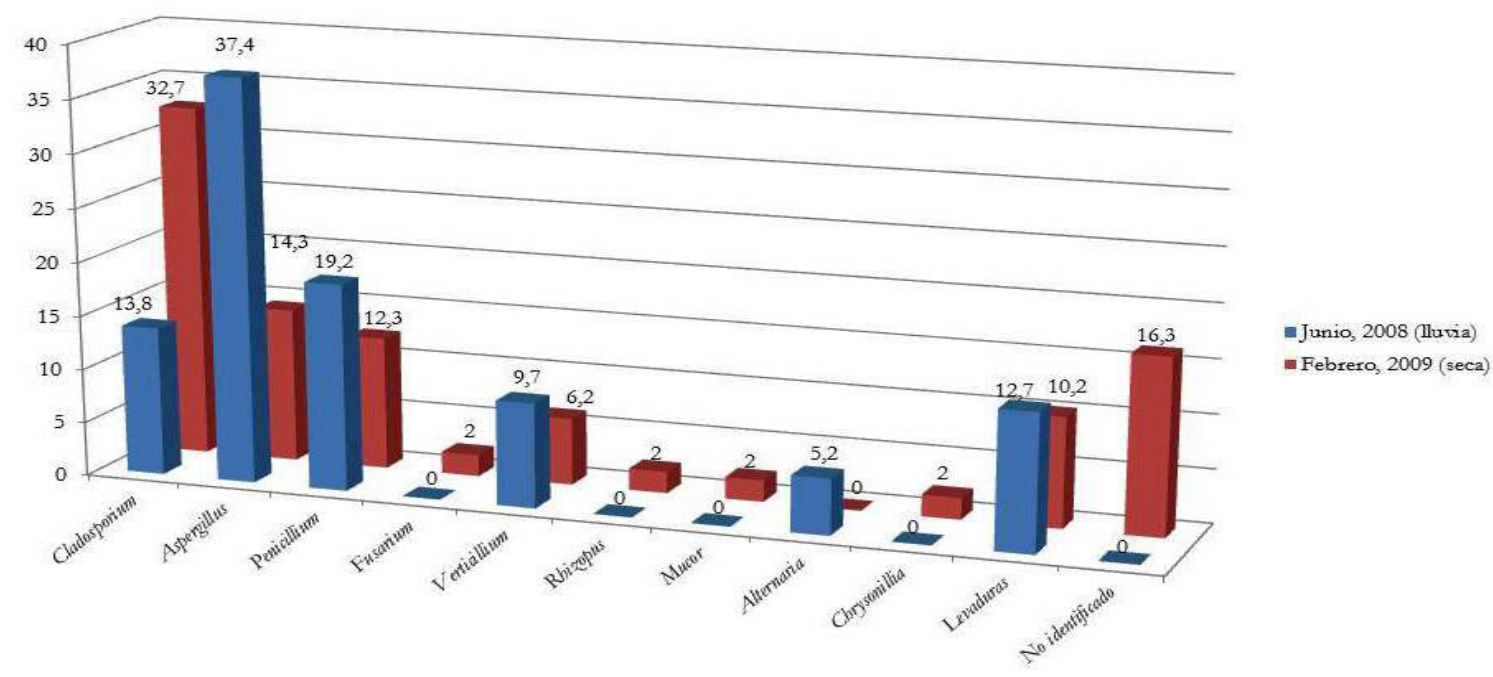

Figura 1.- Densidades relativas en por cientos de los diferentes géneros fúngicos aislados en los ambos muestreos 

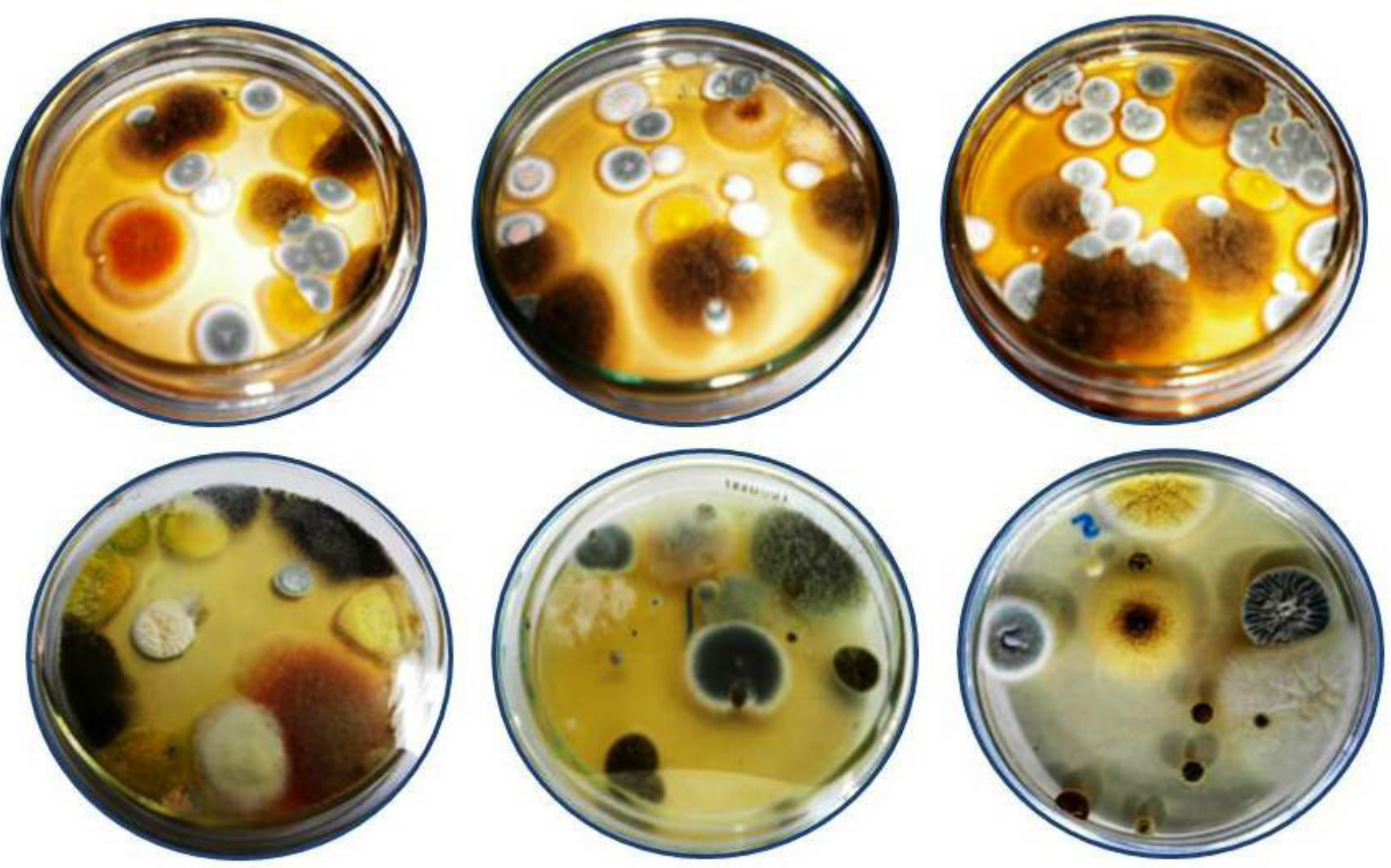

Figura 2.- Ejemplos representativos de los aislamientos fúngicos del aire (superior: aislamientos de época de lluvia; inferior: aislamientos de época de seca)

como los contaminantes fúngicos por excelencia en ambientes interiores de museos, archivos y bibliotecas de nuestro país (Borrego et al. 2007; Borrego et al. 2010; Borrego \& García, 2011), reforzando el criterio de que las especies de Aspergillus y Penicillium representan taxones muy comunes, colonizadores primarios del patrimonio de naturaleza orgánica.

En el muestreo de Febrero 2009 estos géneros se mantuvieron como los más representativos de la micobiota aérea del depósito, siendo el de mayor densidad Cladosporium con $32.7 \%$, seguido por Aspergillus (14.3\%) y Penicillium (12.3\%). Es precisamente Cladosporium el género fúngico aislado con mayor frecuencia en ambientes de archivos y bibliotecas en numerosos estudios previamente realizados en época de seca (Borrego et al. 2010; Borrego, 2005; Borrego \& Garcia, 2011). Estos resultados se corresponden con otros reportes, que señalan a estos géneros fúngicos como los principales contaminantes de ambientes interiores a nivel mundial (Maggi et al., 2000; Valentin, 2001; Rojas et al. 2002; Martínez, 2003; Borrego, 2004; Guiamet et al. 2007; Borrego et al. 2008; Mesquita et al. 2009).

Resultó amplia la diversidad de géneros detectados durante el muestreo de época de seca, a diferencia del efectuado en época de lluvia, donde se detectaron representantes de los géneros Fusarium, Rhizopus, Mucor y Chrysonillia, no detectados durante el mencionado en el mes de Junio. Las diferencias en los géneros detectados entre dichos muestreos se corresponde también con estudios semanales realizados durante un año en ambientes de bibliotecas, donde se obtuvieron en algunos meses géneros no reportados en otros, lo que está en dependencia fundamentalmente de los parámetros ambientales predominantes durante el muestreo y las características propias de las esporas de los diferentes géneros fúngicos reportados (Bueno et al. 2003).

La figura 2 muestra los resultados típicos de los muestreos fúngicos realizados. En la parte superior se puede apreciar un mayor número de aislados con una menor diversidad de colonias, correspondientes al muestreo realizado en época de lluvia, mientras en la parte inferior se aprecian aislamientos menos numerosos pero con mayor diversidad de colonias, correspondientes a la época de seca.

En ambos muestreos se detectaron levaduras con una densidad por encima del $10 \%$, similar a muestreos microbiológicos ambientales en bibliotecas de Venezuela y Argentina (Bueno et al. 2003; Medina et al. 1999) y otros estudios que describen a las levaduras entre los representantes predominantes de la micobiota fúngica de ambientes interiores en museos, archivos y bibliotecas (Li \& Kuo, 1994). Los aislados de levadura correspondieron 

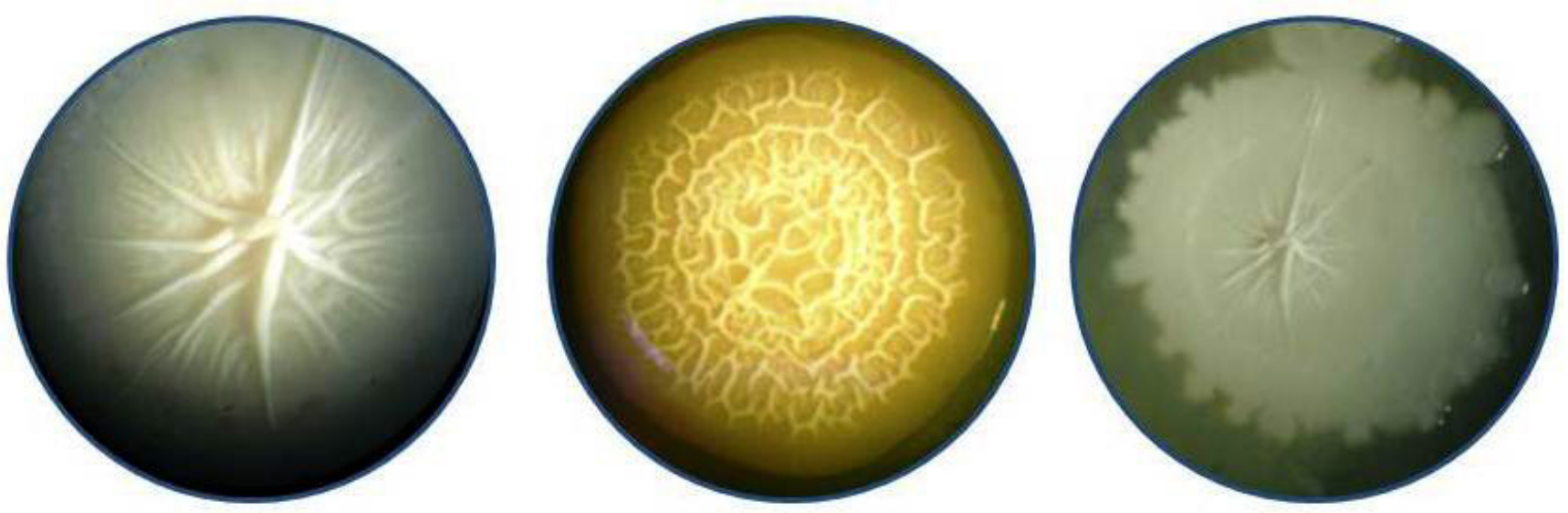

Figura 3.-Caracteres morfo culturales de los aislados de levaduras observados al estereoscopio (30X)

a tres especies diferentes cuya morfología de crecimiento se puede apreciar en la figura 3, las cuales no pudieron identificarse por no contar con las técnicas necesarias.

Caracterización fisiológica de los aislados fúngicos identificados, con mayor densidad relativa

La tabla 2, muestra los resultados de las pruebas fisiológicas cualitativas realizadas para evaluar el potencial deteriógeno de los aislados de los géneros Aspergillus, Cladosporium y Penicillium, los cuales representan géneros muy comunes en el aire del local al mostrar las mayores densidades relativas de aislamiento.

Los aislados analizados fueron capaces de crecer a expensas de papel de filtro y celulosa microcristalina (CMC) como única fuente de carbono, lo que indica que presentan actividad celulolítica en mayor o menor medida. El $60 \%$ de los aislados fúngicos estudiados excretaron pigmentos solubles sobre el papel de filtro; todos los aislados produjeron ácidos que propiciaron una disminución del $\mathrm{pH}$ inicial del medio de cultivo inoculado, destacándose las especies de $A$. niger, $A$. flavus, $A$. oryzae y $A$. terreus, las cuales provocaron una disminución del $\mathrm{pH}$ inicial de medio de inoculación, por debajo de $\mathrm{pH} 4$, demostrando su fuerte acción acidógena y su elevado potencial para provocar hidrolisis acida de la celulosa del papel; mientras el 80 \% mostró actividad proteolítica, resultados que concuerdan con los reportados en otros estudios (Martinez, 2003; Mateus et al, 2004; Borrego et al., 2008; Borrego et al., 2010; Borrego \& Garcia, 2011).

Teniendo en cuenta las propiedades metabólicas de las especies de estos géneros se puede afirmar que, independientemente de que los niveles de contaminación fúngica correspondan a ambientes no contaminados o poco contaminados, estos taxa representan un riesgo de

Tabla 2.- Actividades fisiológicas de las especies correspondientes a los géneros fúngicos aislados con mayores densidades relativas

\begin{tabular}{|c|c|c|c|c|}
\hline Cepa & Actividad celulolítica & Actividad proteolítica & Producción pigmentos & pH \\
\hline A. niger & +++ & + & - & $3,16^{*}$ \\
\hline A. flavus & +++ & + & + & $3,60^{*}$ \\
\hline A. ochraceus & ++ & + & - & 5,55 \\
\hline A. oryzae & ++ & + & + & $3,17^{*}$ \\
\hline A. terreus & ++ & + & - & $3,50^{*}$ \\
\hline A. candidus & ++ & + & + & 5,76 \\
\hline P. chrysogenum & +++ & + & - & 5,65 \\
\hline P. citrinum & ++ & + & + & 5,40 \\
\hline C. cladosporioides & +++ & - & + & 5,10 \\
\hline Cladosporium sp. & ++ & - & + & 5,85 \\
\hline
\end{tabular}

+++: actividad elevada, ++: actividad moderada, +: actividad baja, presencia de pigmento y degradación de gelatina, -: NO producción de pigmento y NO degradación de gelatina.los valores con * alertan sobre la disminución significativa de pH del medio de inoculación 
Tabla 3.- Densidad relativa de los tipos bacterianos aislados en el depósito de fondos documentales del Museo Nacional de la Música

\begin{tabular}{|ccc|}
\hline Bacterias & $\begin{array}{c}\text { Muestreo Junio } \\
\mathbf{2 0 0 8} \text { (lluvia) } \\
\text { DR (\%) }\end{array}$ & $\begin{array}{c}\text { Muestreo Febre- } \\
\text { ro 2009 (seca) } \\
\text { DR (\%) }\end{array}$ \\
\hline $\begin{array}{c}\text { Cocos Gram } \\
\text { positivos }\end{array}$ & 79,80 & 71,25 \\
\hline $\begin{array}{c}\text { Bacilos Gram } \\
\text { positivos }\end{array}$ & 12,60 & 28,74 \\
\hline $\begin{array}{c}\text { Bacilos Gram } \\
\text { negativos }\end{array}$ & 7,60 & - \\
\hline
\end{tabular}

deterioro potencialmente peligroso para las colecciones documentales y es importante regular adecuadamente los valores de HR y T, para evitar que sus esporas puedan germinar y crecer deteriorando de manera sensible, a partir de su actividad metabólica altamente deteriorante, los ejemplares contaminados.

\section{Cepas bacterianas aisladas del aire del local muestreado}

Las colonias bacterianas aisladas muestran una amplia diversidad en sus características morfológicas. La tinción de Gram arrojó resultados similares en ambos muestreos [Tabla 3], con un predominio de bacterias Gram positivas con una densidad relativa del $92.4 \%$ en el primer muestreo ( $79.8 \%$ de cocos y $12.6 \%$ de bacilos) y un $100 \%$ en el segundo ( $71.25 \%$ de cocos y $28.74 \%$ de bacilos), resultados similares a los reportados en estudios realizados en diferentes depósitos del Archivo Nacional de la República de Cuba (Borrego et al., 2007). Solo se hallaron formas bacilares Gram negativas durante el primer muestreo, para un $7.6 \%$ del total.

Independientemente del aporte microbiano provocado por la penetración del polvo en los ambientes de interiores, se plantea que las bacterias Gram positivas también pueden ingresar al interior de los depósitos como consecuencia de la actividad del hombre en el interior de estos locales, ya que muchas de ellas pueden formar parte de la piel y las mucosas del organismo humano (Zhu et al., 2003).

La densidad relativa de bacterias Gram positivas y negativas coincide con los reportes de otros autores que obtuvieron una concentración de formas Gram negativas inferiores a las Gram positivas (García et al., 2005; De la Rosa et al. 2002), lo que se debe fundamentalmente a que estas últimas son más resistentes a la desecación al poseer una pared celular más gruesa y rígida.

Teniendo en cuenta el comportamiento de la HR y la $T$ se puede afirmar que a pesar del elevado nivel de contaminación bacteriana, estas no representan un peligro potencial de deterioro para las colecciones almacenadas ya que requieren una actividad de agua superior a 0.95, que sólo alcanzarían los documentos en condiciones de HR superiores al $95 \%$, cercanas a la saturación o en casos de condensación o fenómenos de filtración o inundación que provocaran el mojado de las colecciones.

\section{Conclusiones}

Las concentraciones microbianas encontradas en el muestreo de Junio 2008 (lluvia) reflejaron valores de concentración de bacterias propios de ambientes altamente contaminados y poco contaminados para hongos según criterios propuestos por Omeliansky. En el muestreo de Febrero 2009 (seca) estos valores se mantuvieron de igual forma solo para las bacterias y para hongos disminuyó a la categoría de no contaminado.

Los aislados fúngicos identificados pertenecen a los géneros Aspergillus, Penicillium, Cladosporium, Fusarium, Alternaria, Rhizopus, Mucor, Verticillium y Chrysonillia.

Los aislados del género Aspergillus tuvieron la mayor densidad en el primer muestreo (Junio 2008), seguido de Penicillium y Cladosporium, mientras en el segundo (Febrero 2009) Cladosporium ocupó el primer lugar seguido de Aspergillus y Penicillium. Entre las bacterias hubo predominio de Gram positivas en ambos muestreos.

Todas los aislados fúngicos evaluados fisiológicamente mostraron actividad celulolítica y liberaron ácidos al medio, lo cual evidencia que pueden propiciar el biodeterioro de los soportes documentales por lo que podemos afirmar que existe un significativo riesgo potencial de deterioro fúngico en el depósito estudiado a tener en cuenta en el plan integrado de lucha contra plagas de las estrategias de conservación preventiva del museo.

Se encontraron diferencias significativas $(p \leq 0,05)$ entre los dos muestreos realizados para la carga fúngica y microbiana total, existiendo una muy alta correlación positiva entre la concentración fúngica y los parámetros climáticos HR y T, con una perfecta correlación positiva entre los mismos.

\section{Bibliografía}

ABDEL HAMEED, A.A., AYESH, A.M., RAZIK MOHAMED, M.A., \& ABDEL MAWLA, H.F. (2012). Fungi and some mycotoxins producing species in the air of soybean and cotton mills: a case study. Atmospheric Pollution Research, 3: 126-131.

AWAD, AH \& MAWLA, AH. (2012): Sedimentation with the Omeliansky formula as an accepted technique for quantifying airborne fungi. Pol. J. Elnviron. Study; 21 (6): 1539-1541.

BARNET, H.L. \& HUNTER, B.B. (1997). Illustrated Genera of Imperfect Fungi. New York, USA: MacMillan Publisher Co. 218 pp

BOGOMOLOVA, EV \&, KIRTSIDELI, I. (2009): Airborne fungi in 
four stations of the St. Petersburg Underground railway system. International Biodeterioration and Biodegradation; 63:156-61.

BORREGO, S. (2004). Método para contabilizar microorganismos del aire en ambientes de archivos y bibliotecas. Boletín Patrimonio y Desarrollo; 11:8-9.

BORREGO, S (2005): El edificio de archivo: su influencia en la contaminación microbiana ambiental, el biodeterioro y la salud del personal. IV Coloquio Iberoamericano del Papiro a la Realidad Virtual, Casa de las Américas, La Habana, Cuba.

BORREGO, S., GUIAMET, P., PONS, V., GÓMEZ DE SARAVIA, S \& PERDOMO, I. (2007). Estudio de la microbiota aislada de documentos especiales y del aire de los depósitos donde estos se almacenan. Taller sobre la conservación del patrimonio documental y la prevención contra catástrofes en países de clima tropical. ISBN 978-959-7196. La Habana, Cuba.

BORREGO, S; PONS, V \& PERDOMO I. (2008). La contaminación microbiana del aire en dos depósitos del Archivo Nacional de la República de Cuba. Revista CENIC Ciencias Biológicas; 39:63-8.

BORREGO, S.; GUIAMET, P.; GÓMEZ DE SARAVIA, S.; BATISTINI, P.; GARCÍA, M.; LAVÍN, P.; PERDOMO; I. (2010a). The quality of air at archives and the biodeterioration of photographs. International Biodeterioration and Biodegradation, 64: 139-145.

BORREGO, S., PERDOMO I., GUIAMET P., GÓMEZ S. (2010 b): Study of the microbial concentration in the air in repositories of the National Archive of Cuba. AUGMDOMUS, 1:114-133.

BORREGO, S. \& GARCÍA, M. (2011): Comportamiento de la concentración microbiana aérea en la Fototeca del Archivo Nacional de Cuba. Revista CENIC Ciencias Biológicas; 42(2), pp. 61-67.

BORREGO, S., PERDOMO, I., DE LA PAZ, J., GÓMEZ DE SARAVIA, S., GUIAMET, S. (2011 b): Relevamiento microbiológico del aire y de materiales almacenados en el Archivo Histórico del Museo de La Plata, Argentina y en el Archivo Nacional de la República de Cuba. Revista del Museo de La Plata, Sección Botánica, 18: 1-18.

BORREGO, S.; LAVIN, P.; PERDOMO, I.; GÓMEZ DE SARAVIA, S.; Y GUIAMET, P. (2012): Determination of Indoor Air Quality in Archives and Biodeterioration of the Documentary Heritage. International Scholarly Research Network, ISRN Microbiology, doi:10.5402/2012/680598

BUENO, D.J., SILVA, J.O. \& OLIVER G. (2003). Hongos ambientales en una biblioteca: un año de estudio. Anales de Documentación; 6:27-34.

CANEVA, G., NUGARI, P.M \& SALVADORI, O. (2000): Métodos de prevención del biodeterioro. En: La Biología en la Restauración. Nerea S.A. (Ed). pp. 149-164.

CAPPITELLI, F., FERMO, P., VECCHI, R., PIAZZALUNGA, A., VALLI, G., ZANARDINI, E. \& SORLINI, C. (2009): Chemical-physical and microbiological measurements for indoor air quality assessment at the Granada Historical Archive, Milan (Italy). Water Air Soil Pollut, 201: 109-120.

CASADESÚS, L. \& ROJAS, T.I. (1981). Micología. Manual Práctico. Ed. MES. 99 p.

CASSARES, N.C. (2007): Calidad del aire interior. En: Taller de Preparación para desastres. Recuperación de los daños biológicos en colecciones afectadas por desastres. Instituto de Historia de Cuba.

CRESPO, C. \& VIÑAS, V. (1984): La preservación y restauración de documentos y libros en papel: Un Estudio del Ramp con directrices. UNESCO. pp.109.

DE LA ROSA, M.C., MOSSO M.A. \& ULLÁN C. (2002): El aire: hábitat y medio de transmisión de microorganismos. Observatorio Medioambiental. ISSN: 1139-1987 (5): 375-402.

FLORIAN, M.L.E. (2004) Fungal facts. Solving fungal problems in heritage collections. Archetype Publications Ltd. London: UK. p. 25-109.

GARCÍA, N., ARAUJO, I., FERNÁNDEZ, M., SALCEDO, W., CÁRDENAS, C., FERNÁNDEZ, J., HERRERA, L., YABROUDI, S. \&. ANGULO, N. (2005). Calidad microbiológica y fisicoquímica del aire en tres laboratorios de la Facultad de Ingeniería de la Universidad de Zulia. CIENCIA; 13 (2): 182-192.

GUIAMET P.S, GÓMEZ DE SARAVIA S.G, BATTISTONI P, BORREGO S, DE LA PAZ J. \& PONS V. (2007) Evaluación microbiológica de los materiales almacenados en el Archivo Histórico del Museo de La Plata, Argentina y en el Archivo Nacional de la República de Cuba. En: Patrimonio cultural: la Gestión, el Arte, la Arqueología y las Ciencias Exactas, 1ra ed. Vázquez C., Martín Palacios O, editores. Buenos Aires, Argentina: Comisión Nacional de Energía Atómica - CNEA: p. 25-30.

INDOOR AIR QUALITY. Bioaerosols: Bacteria Endotoxin. (2004). [Consultado 23 octubre de 2008].Disponible: http:// wwwindoorallergyrelief.com/_index.php/30.

KASPRZYK, I \& WOREK, M. (2006); Airborne fungal spores in urban and rural environments in urban and rural environments in Poland. Aerobiologia, 22:169-176.

KOŁWZAN B., ADAMIAK W., GRABAS K. \& PAWEŁCZYK, A. (2006) Microbiology of air. In: Introduction to Environmental Microbiology. Oficyna Wydawnicza Politechniki WrocŁawskiej. Wrocław. [Consultado 25 junio 2008]. Disponible en: http:// www.oficyna.pwr.wroc.pl

LI, C. \& KUO, Y. (1994). Characteristics of airborne microfungi in subtropical home. Science Total Environment; 155 (3). 266-271. MAGGI, O., PERSIANI, A.M., GALLO, F., VALENTI, P.\& PASQUARIELLO, G. (2000). Airborne fungal spores in dust present in archives: proposal for a detection method new for archival materials. Aerobiología; 16:429-34. 
MARTÍNEZ, P. (2003). Determinación de la acidez producida por hongos contaminantes en bienes culturales. Boletín Patrimonio y Desarrollo; 9:3-11.

MATEUS, J., PEÑA, D., PEÑA, G., ROJA, A., ROJAS, J., ZAMBRANO, $S$. et al. (2004). Seguimiento y control de biodeterioro microbiológico en documentos de interés histórico en el Archivo General de La Nación. Revista de la Facultad de Ciencias Pontificia Universidad Javeriana; 9:37-46.

MEDINA, L., TUOZZO, A., HERRERA, J., PEROZO, Y. \& GONZÁLEZ, L. (1999). Estudio de hongos en bibliotecas de la universidad de Carabobo-Valencia. 3(1).

MESQUITA, N., PORTUGAL, A., VIDEIRA, S., RODRÍGUEZECHEVERRÍA, S., BANDEIRA, A.M.L., SANTOS, M.J.A. et al. (2009). Fungal diversity in ancient documents. A case study on Archive of the University of Coimbra. International Biodeterioration and Biodegradation; 63:626-29.

NEVALAINEN, A. \& MORAWASKA, L. (2009). Biological Agents in Indoor Environments. Assessment of Health Risks. Work conducted by a WHO Expert Group between 2000-2003. http:// www.ilaqh.qut.edu. au/Misc/BIOLOGICAL_AGENTS_2009.pdf.

NOVAKOVIC, M., KARAMAN, M, RADNOVIC, D, RADISIC, P. \& SIKOPARIJA, B. (2013). Monitoring of fungal spores in the indoor air of preschool institution facilities in novi sad. Jour. Nat. Sci, Matica Srpska Novi Sad, № 124, 297-305.

NUGARI, M.P. Y ROCCARDI, A. (2001): Aerobiological investigations applied to the conservation of cultural heritage. Aerobiologia; 17: 215-223.

PASQUARELLA,C; PITZURRA, O; AND SAVINO, A. (2000): The index of microbial air contamination. Journal of Hospital Infection, 46: 241-256.

PINZARI, F., FANELLI, C., CANHOTO, O., \& MAGAN, N. (2004). Electronic nose for the early detection of moulds in libraries and archives. Indoor Built Environment; 13: 387-395.

PITT, J.I. (2000). A laboratory guide to common Penicillium species. Food Science Australia. Third Edition. 196 p.

PITT, J.I. \& KLICH, M.A. (1994). A computer assisted synoptic key to common Penicillium species and their teleomophs (PENKEY).CSI Division of Food Processing, Australia. 27p.

PONS, V. \& ROJAS, T.I. (2003). Microbiota contaminante en el Museo Antropológico Montané. Trabajo de Diploma, Facultad de Biología, Universidad de la Habana, Cuba.

RADLER DE AQUINO, F. \&, DE GÓES, L.F. (2000). Guidelines for indoor air quality in offices in Brazil. Proceedings of Healthy Buildings; 4:549-54.

ROJAS, T.I., MARTíNEZ, E., GÓMEZ, Y. \& ALVARADO, Y. (2002). Airborne spores of Aspergillus species in cultural institutions al
Havana University. Grana;41:190-3

ROJAS, T.I. \& MARTÍNEZ, E. (2000). Monitoreo microbiano del aire: Criterios metodológicos. IV Taller de la Cátedra de Medio Ambiente, CITMA. Contribución a la Educación y la Protección Ambiental, 1.

SÁNCHIS, J (2002). Los nueve parámetros más críticos en el muestreo microbiológico del aire. Rev. Técnicas de Laboratorio, 276: 858- 862.

SMITH, G. (1980). Ecology and Field Biology. Harper y Row. New York. 835 p.

STRYJAKOWSKA-SEKULSKA, M., PIOTRASZEWSKA-PAJĄK, A., SZYSZKA, A., NOWICKI, M.,FILIPIAK, M. (2007): Microbiological Quality of Indoor Air in University Rooms. Polish Journal of Environmental Studies. Vol. 16, No. 4, 623-632.

TOIVOLA, M., ALM, S., REPONEN, T., KOLARI, S. \& NEVALAINEN, A. (2002). Personal exposure and microenvironmental concentration of particles and bioaerosols. Journal Environment Monitory; 4: 166-174.

ULEA, E., LIPŞA, F.D., IRIMIA, N. \& BĂLĂU, AM. (2009): Survey of indoor airborne fungi in different educational institutions from lasi, România. Lucrări Ştiinţifice, seria Agronomie, 52:518-523.

VALENTÍN, N., VAILLANT, M. \& GUERRERO, H. (1997). Programa de control integrado de plagas en bienes culturales de países de clima mediterráneo y tropical. Apoyo; 7:13-21.

VALENTÍN, N. (2001). Microbial contamination and insect infestation in Spanish museums, archives and libraries. COALITION; 3:5-6.

VALENTÍN, N. (1974): Contaminación microbiana en museos, archivos y bibliotecas. Revista de Archivos, Bibliotecas y Monumentos. Tomo LXXVII. pp.747- 767.

VILLALBA, L.S., MIKAN, J.F. \& SANCHEZ, J. (2004). Actividades hidrolíticas y caracterización isoenzimática de poblaciones microbianas aisladas del patrimonio documental del Archivo General de Colombia. NOVA; 2:50-8.

YASSIN, MF. \& ALMOUQATEA, S.(2010). Assessment of airborne bacteria and fungi in an indoor and outdoor environment. Int. J. Environ. Sci. Tech., 7 (3): 535-544.

ZHU, H., PHELAN, P. E., DUAN, T., RAUPP, G.B. , FERNANDO, H.J.S. \& CHE, F. (2003). Experimental study of indoor and outdoor airborne bacterial concentrations in Tempe, Arizona, USA. Aerobiologia; 19:201-211 


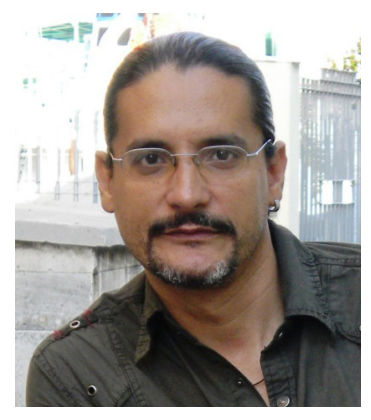

\section{Julio César Rodríguez García}

jcesar2015@mail.com

Licenciado en Biología y Master en Microbiología por la Facultad de Biología de la Universidad de la Habana. Investigador y Profesor Auxiliar de la Universidad de las Artes. Especialista en Conservación Preventiva y Biodeterioro del Patrimonio Cultural, con mas de 12 años dedicados a la investigación cientifíca al servicio de la conservación del Patrimonio Cultural y la formación universitaria de conservadores restauradores.

Artículo enviado el 30/06/2015

Artículo aceptado el 09/03/2016 